\title{
Nonsteroidal Antiinflammatory Drugs and Colorectal Cancer
}

\author{
Joshua E. Muscat, M.P.H., Steven D. Stellman, Ph.D., M.P.H., \\ and Ernst L. Wynder, M.D.
}

\begin{abstract}
Background. The association between the use of nonsteroidal antiinflammatory drugs (NSAID) and large bowel cancer was examined in a hospital-based casecontrol study of 511 patients with colorectal cancer and 500 age-sex matched control subjects.

Methods. Regular NSAID use was defined as at least 3 times per week for 1 or more years before the date of hospital admission. Odds ratios (OR) were calculated by the duration of NSAID use and according to the medical reasons given for taking NSAIDs.

Results. The prevalences of regular NSAID use were $15 \%$ for male patients, $8 \%$ for female patients, and $20 \%$ for control subjects. Overall, NSAID use was associated with a statistically significant risk reduction in men (OR $=0.64 ; 95 \%$ confidence interval $[\mathrm{CI}], 0.42-0.97)$ and in women (OR $=0.32 ; 95 \% \mathrm{CI}, 0.18-0.57)$. The estimate decreased with duration among men but increased with duration among women. The risk reduction among patients who took NSAIDs to prevent heart disease was 0.67 (95\% CI, 0.38-1.13) for men and 0.43 (95\% CI, 0.12-1.59) for women. For treating headache pain, the $\mathrm{OR}$ was $0.5(95 \%$
\end{abstract}

From the Division of Epidemiology, American Health Foundation, New York, New York.

Supported by Public Health Service grants CA-32617 and CA17613 from the National Cancer Institute, National Institutes of Health, Department of Health and Human Services, and, in part, by a grant from the McNeil Consumer Products Company, Fort Washington, Pennsylvania.

The authors thank the following physicians and hospitals for their participation: Marc Citron, M.D., Long Island Jewish Medical Center (New Hyde Park, NY); Robert Burakoff, M.D., Winthrop University Hospital (Mineola, NY); Ronald Blum, M.D., New York University Medical Center (New York, NY); Randall Harris, M.D., Ph.D., Ohio State University (Columbus, OH); Alfred Neugut, M.D., Ph.D., College of Physicians and Surgeons, Columbia University (New York, NY). We also thank Gary Williams, M.D., John Weisburger, Ph.D., and Bandaru Reddy, Ph.D., of the American Health Foundation, and Clark Heath, M.D., of the American Cancer Society, for expert comments, and our interviewers, Rebecca Moldwin, M.P.H., Cindy Patterson, B.A., and Marion Rogers, R.N.

Address for reprints: Joshua E. Muscat, M.P.H., Division of Epidemiology, American Health Foundation, 320 East 43rd Street, New York, NY 10017.

Received December 8, 1993; revision received March 18, 1994; accepted March 24, 1994.
CI, 0.23-1.09) for men and $0.64(95 \%$ CI, 0.25-1.62) for women. The use of NSAID was not found to be associated with the stage of cancer at diagnosis. The OR for daily acetaminophen use was 1.07 ( $95 \% \mathrm{CI}, \mathbf{0 . 3 5}-3.23)$ for men and $0.59(95 \% \mathrm{CI}, 0.27-1.25)$ for women.

Conclusions. The regular use of NSAIDs was associated with an overall significant risk reduction of colorectal cancer in men and in women. Among female patients, the greater protective effect associated with short term NSAID use compared with long term NSAID use may reflect a sampling bias. Cancer 1994; 74:1847-54.

Key words: aspirin, acetaminophen, colon, rectum, prostaglandins.

Nonsteroidal antiinflammatory drugs (NSAIDs) are chemopreventive agents in experimentally-induced colon cancer models. ${ }^{1-13}$ A possible mechanism for this action is the inhibition of select pathways of prostaglandin synthesis. Certain prostaglandins have been shown to increase cell proliferation and tumor growth, ${ }^{14,15}$ and affect immune response. ${ }^{16}$ Another type of analgesic, acetaminophen, also has been suggested to be a prostaglandin synthesis inhibitor, although the mechanism of its action is poorly understood. ${ }^{17}$

The relationship between NSAIDs and colorectal cancer have been studied in several human populations (Table 1). Regular intake of NSAIDs reduced the risk or mortality from colon or colorectal cancer in some epidemiologic studies, ${ }^{18-22}$ although one prospective study did not support such an association. ${ }^{23}$ No effect of aspirin was observed in a randomized clinical trial of low dose aspirin use after 5 years of follow-up. ${ }^{24}$ However, regular aspirin use reduced the occurrence of adenomas in a case-control study ${ }^{25}$ and in a separate clinical trial of patients who had a resection of a large bowel adenoma after 1 year of follow-up. ${ }^{26}$

Despite these fairly consistent findings, it has not been shown that long term users of NSAIDs have a lower risk of colon cancer than short term users. In addition, the reduction in colorectal cancer risk associated 


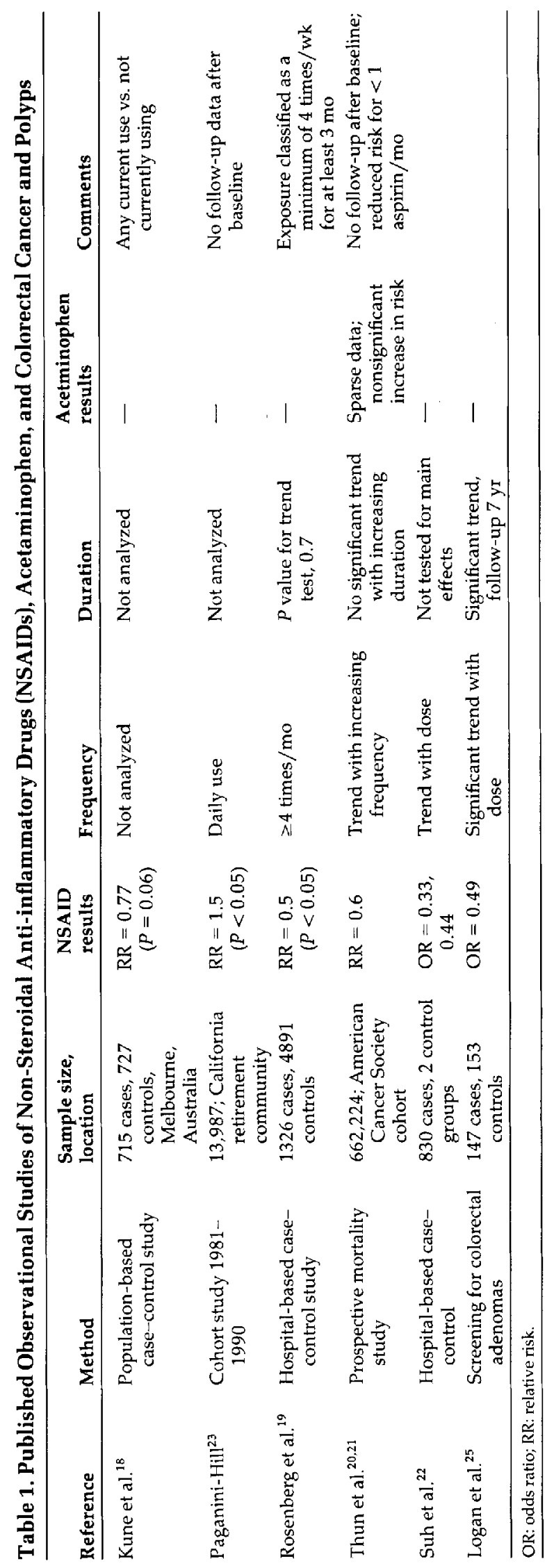


with NSAID intake in some studies may have reflected the lifestyle or health behaviors of the NSAID users rather than the medication itself. The current case-control study examines regular NSAID and acetaminophen intake among newly diagnosed subjects according to the frequency, duration, and medical reasons given for their usage.

\section{Methods}

A case-control study of large bowel cancer was designed specifically to assess the effects of analgesic use. Five hundred, eleven patients with histologically confirmed colorectal cancer ( 346 colon patients, 165 rectum patients) were interviewed between 1989 and 1992 in five hospitals by trained personnel using a standardized questionnaire. Control subjects included 500 patients who were matched to each case patient by sex, race, hospital, age ( \pm 5 years), and month of interview. Eligible control subjects included patients with conditions unrelated to NSAID use. Excluded specifically as admitting diagnoses were heart attacks, arthritis, and headaches. The major control diagnoses were cancer $(18.7 \%)$, genitourinary conditions $(12.4 \%)$, musculoskeletal/skin disorders (11.1\%), injuries $(10.2 \%)$, slipped disks $(8.9 \%)$, and benign prostatic hyperplasia $(8.1 \%)$. Informed consent was obtained from all subjects. Information was collected on sociodemographic variables, medical history, family history of cancer, pregnancy history, lifetime physical activity, smoking, and alcohol use. A food frequency section was used to obtain information on the major sources of total dietary fat and fiber.

Subjects were asked the following questions: "Have you ever taken any over-the-counter pain relievers?" and "Have you ever taken any prescription pain relievers?" Information was recorded on the types and brand names of the pain relievers, the frequency and duration of use, the age of the patients when they first used the products, and the specific medical reasons given for taking the medications. The pathology reports of the case patients were examined to determine the site and stage of the tumor. Greater than $90 \%$ of the patients who were approached participated.

Nonsteroidal antiinflammatory drugs include aspirin, ibuprofen, indomethacin, and others. Acetaminophens were defined as any pain relievers containing acetaminophen exclusively (e.g., regular and extrastrength Tylenol [McNeil Consumer Products, Ft. Washington, PA], aspirin-free Anacin [Whitehall Laboratories, New York, NY]). Most commercial brands contained $100 \%$ acetaminophen as the active ingredient. A few patients took products formulated with both acetaminophen and aspirin. Regular use of NSAIDs and acetaminophen was defined as at least 3 times per week for at least 1 year before the interview. This definition reduced the possible bias that could have resulted from patients taking pain relievers to treat the symptoms of their illness. Only one male case patient and one control subject took acetaminophen daily but discontinued use more than 1 year before the interview. Among the women, $1 \%$ of both case patients and control subjects took acetaminophen regularly but discontinued use 1 year before the interview.

The initial data analysis showed that the use of acetaminophen on a less-than-daily basis was not associated with the risk of colorectal cancer. We therefore present the risk estimates for daily acetaminophen use. Acetaminophen users were compared with patients who did not use both acetaminophen and NSAIDs. Matched-pair odds ratios (ORs) and $95 \%$ confidence intervals (CIs) were calculated by taking the ratio of discordant case-control pairs. ${ }^{27}$

Although the eligibility criteria for the hospital controls excluded such conditions as arthritis and headaches, there may be other unknown medical conditions that are related to aspirin intake. Because it is important that the control group represent the population at risk, possible bias resulting from the selection of hospital subjects can be minimized by using control subjects with a variety of diagnoses. ${ }^{28}$ There were 180 distinct diagnoses among the control group. The control subjects were grouped according to major diagnostic categories, and the prevalence of NSAID use was examined separately for each category.

\section{Results}

The basic characteristics of the case patients and control patients are shown in Table 2. Case patients and control subjects had similar ages, levels of education, and religious affiliations. There was a slightly higher proportion of college graduates and Jewish males in the control group than in the case group.

Thirty-eight percent of the case subjects and $47 \%$ of the control subjects took NSAIDs for at least 1 year (Table 2). Fifteen percent of male case patients used NSAIDs regularly (e.g., at least 3 times a week for at least 1 year) compared with $20 \%$ of control subjects. In addition, a greater percentage of male control subjects took NSAIDs 1-2 times per week for 9 or more years, as compared with male case patients ( $4.3 \%$ vs. $1.8 \%$ ). Aspirin was the most common type of NSAID taken. Among women, $7.5 \%$ of case patients and $19.6 \%$ of control subjects took NSAIDs regularly. NSAIDs were taken regularly for as long as 40 years by some men and women.

Forty-four percent of males and $62 \%$ of females 
Table 2. Characteristics of 511 Colorectal Cases and 500 Controls

\begin{tabular}{|c|c|c|c|c|}
\hline & \multicolumn{2}{|c|}{ Males } & \multicolumn{2}{|c|}{ Females } \\
\hline & $\begin{array}{l}\text { Cases } \\
(n=283)\end{array}$ & $\begin{array}{l}\text { Controls } \\
(n=276) \\
\end{array}$ & $\begin{array}{l}\text { Cases } \\
(n=228)\end{array}$ & $\begin{array}{l}\text { Controls } \\
(n=224)\end{array}$ \\
\hline \multicolumn{5}{|l|}{ Age (yr) } \\
\hline$<45$ & $13(4.6)$ & $15(5.4)$ & $11(4.8)$ & $12(5.4)$ \\
\hline $45-54$ & $21(7.4)$ & $23(8.3)$ & $34(14.9)$ & $31(13.8)$ \\
\hline $55-64$ & $75(26.5)$ & $74(26.8)$ & $57(25.0)$ & $58(25.9)$ \\
\hline $65-74$ & $124(43.8)$ & $136(49.3)$ & $87(38.2)$ & $98(43.8)$ \\
\hline$>74$ & $50(17.7)$ & $28(10.1)$ & $39(17.1)$ & $25(11.2)$ \\
\hline \multicolumn{5}{|c|}{ Education (yr) } \\
\hline$<12$ & $51(18.1)$ & $40(14.5)$ & $37(16.3)$ & $33(14.7)$ \\
\hline 12 & $94(33.3)$ & $79(28.6)$ & $102(44.9)$ & $93(41.5)$ \\
\hline $13-15$ & $56(19.9)$ & $60(21.7)$ & $46(20.3)$ & $50(22.3)$ \\
\hline 16 & $33(11.7)$ & $45(16.3)$ & $20(8.8)$ & $24(10.7)$ \\
\hline$>16$ & $48(17.0)$ & $52(18.8)$ & $22(9.7)$ & $24(10.7)$ \\
\hline \multicolumn{5}{|c|}{ Duration of regular NSAID use* $/$ yr } \\
\hline Nonuser & $240(84.8)$ & $219(79.4)$ & $210(92.5)$ & $181(80.4)$ \\
\hline $1-4$ & $17(6.0)$ & $16(5.8)$ & $4(1.8)$ & $19(8.4)$ \\
\hline $5-9$ & $15(5.3)$ & $16(5.8)$ & $1(0.4)$ & $8(3.6)$ \\
\hline$>10$ & $11(3.9)$ & $25(9.1)$ & $12(5.3)$ & $17(7.6)$ \\
\hline Ever & $43(15.2)$ & $57(20.6)$ & $17(7.5)$ & $44(19.6)$ \\
\hline \multicolumn{5}{|c|}{ Frequency of NSAID use/wk† } \\
\hline Nonuser & $177(62.5)$ & $139(50.4)$ & $142(62.6)$ & $126(56.0)$ \\
\hline$<1$ & $57(20.1)$ & $63(22.8)$ & $51(22.5)$ & $39(17.3)$ \\
\hline $1-2$ & $6(2.1)$ & $17(6.2)$ & $17(7.5)$ & $37(7.1)$ \\
\hline $3-6$ & $12(4.2)$ & $13(4.7)$ & $4(1.8)$ & $5(2.2)$ \\
\hline$\geq 7$ & $31(11.0)$ & $44(15.9)$ & $13(5.7)$ & $39(17.3)$ \\
\hline \multicolumn{5}{|c|}{ Acetaminophen use $\ddagger$} \\
\hline Nonuser & $276(97.5)$ & $268(97.1)$ & $212(93.4)$ & $207(89.3)$ \\
\hline User & $7(2.5)$ & $8(2.9)$ & $15(6.6)$ & $24(10.7)$ \\
\hline $\begin{array}{l}\text { Values are no. } \\
\text { * At least } 3 \text { tim } \\
\dagger \text { For } 1 \text { or mor } \\
\ddagger \text { Daily use for }\end{array}$ & & & & \\
\hline
\end{tabular}

had ever taken acetaminophen. Only $3 \%$ of male case patients and $3 \%$ of male control subjects took acetaminophen daily for 1 year or more, compared with $6 \%$ of female case patients and $11 \%$ of female control subjects, respectively. Most of the acetaminophen taken by the patients was over-the-counter medication. In contrast to the use of aspirin, no male patients had taken acetaminophen regularly for more than 9 years.

The proportions of regular NSAID users ( $\geq 3$ times per week for 1 or more years) in the control subgroups were: $12 \%$ of 92 control subjects with cancer or benign tumors (breast, prostate, melanoma, uterus, others); $25 \%$ of 79 control subjects with skin or musculoskeletal conditions; $21 \%$ of 61 control subjects with genitourinary conditions; $20 \%$ of 50 control subjects with injuries; $36 \%$ of 44 control subjects with slipped disks; $17 \%$ of 41 control subjects with digestive conditions (mostly hernia and peritonitis); $19 \%$ of 31 control subjects with neurologic conditions; and $10 \%$ of 39 male case patients with benign prostatic hyperplasia. There were little proportional differences in NSAID use between men and women in each of these categories.

The ORs for regular NSAID and acetaminophen use are shown in Table 3. The ORs for men who took NSAIDs regularly were $0.77(95 \% \mathrm{Cl}, 0.34-1.75)$ for $1-$ 4 years of use, 0.93 (95\% CI, $0.45-1.97)$ for $5-9$ years of use, and 0.47 ( $95 \% \mathrm{CI}, 0.21-0.94)$ for more than 9 years of use. The OR for men who took NSAIDs 1-2 times per week for 9 or more years was 0.42 (95\% CI, 0.151.15). Among women who took NSAIDs regularly, there was a significant decrease in risk for 1-4 years of use $(\mathrm{OR}=0.17 ; 95 \% \mathrm{CI}, 0.06-0.49)$, and for 5-9 years of use (OR $=0.13 ; 95 \% \mathrm{CI}, 0.02-1.39)$. The relative risk for more than 9 years of regular NSAID use was 0.60 (95\% CI, 0.26-1.36). Overall, regular NSAID use was associated with a significant risk reduction in both men 
Table 3. Matched-Pair Odds Ratio of Nonsteroidal Anti-inflammatory Drugs (NSAIDs) and Acetaminophen Use in Relation to Colorectal Cancer

\begin{tabular}{|c|c|c|c|c|c|c|}
\hline & \multicolumn{3}{|c|}{ Males } & \multicolumn{3}{|c|}{ Females } \\
\hline & Ratio & $O R$ & $95 \% \mathrm{CI}$ & Ratio & OR & $95 \% C I$ \\
\hline \multicolumn{7}{|l|}{ Regular NSAIDs* } \\
\hline $1-4$ yr & $10 / 13$ & 0.77 & $0.34-1.75$ & $3 / 18$ & 0.17 & $0.06-0.49$ \\
\hline $5-9 \mathrm{yr}$ & $13 / 14$ & 0.93 & $0.45-1.97$ & $1 / 8$ & 0.13 & $0.02-1.39$ \\
\hline$>9 \mathrm{yr}$ & $8 / 17$ & 0.47 & $0.21-0.94$ & $9 / 15$ & 0.60 & $0.26-1.36$ \\
\hline (1-2 times $/ w k$ for $>9 \mathrm{yr})$ & $5 / 12$ & 0.42 & $0.15-1.15$ & & & \\
\hline Total & $36 / 56$ & 0.64 & $0.42-0.97$ & $13 / 41$ & 0.32 & $0.18-0.57$ \\
\hline \multicolumn{7}{|l|}{ Reasons for NSAID usage } \\
\hline Prevention & $21 / 32$ & 0.66 & $0.38-1.13$ & $3 / 7$ & 0.43 & $0.12-1.59$ \\
\hline Arthritis & $6 / 6$ & 1.00 & - & $3 / 23$ & 0.13 & $0.05-0.36$ \\
\hline Headache/other $\neq$ & $9 / 18$ & 0.50 & $0.23-1.09$ & $7 / 11$ & 0.64 & $0.25-1.62$ \\
\hline Acetaminophen $\xi \geq 1 \mathrm{yr}$ & $7 / 6$ & 1.07 & $0.35-3.23$ & $17 / 12$ & 0.59 & $0.27-1.25$ \\
\hline
\end{tabular}

Values are cases and controls who took acetaminophen only and excludes compound products. The referent group includes subjects who took neither acetaminophen and NSAIDs. OR: odds ratio; $\mathrm{Cl}$ : confidence interval.

* $\geq 3$ times per week.

† Includes regular NSAID users and men who used NSAIDs for 1-2 times per week for $>9$ years.

$\ddagger$ Includes 5 male subjects and 4 female subjects who reported taking NSAIDs for treating trauma pain.

$\S$ Daily use, unmatched ORs.

and women. No relationship with colorectal cancer was observed in women who used NSAIDs less than three times per week. There were little differences in risk when comparing the effects of NSAIDs between the left-sided colon and the right-sided colon.

Women took NSAIDs on a regular basis primarily to treat arthritis and headaches, whereas the majority of men stated that they took NSAIDs to prevent heart disease. When the risk of colorectal cancer according to the reason given for taking NSAIDs (Table 3) was examined, a decreased risk was found for men and women who took NSAIDs to prevent heart disease (men: $\mathrm{OR}=0.66 ; 95 \% \mathrm{CI}, 0.38-1.13$; women: $\mathrm{OR}=$ $0.43 ; 95 \% \mathrm{Cl}, 0.12-1.59)$ and for treating headache or other pain (men: $\mathrm{OR}=0.5 ; 95 \% \mathrm{CI}, 0.23-1.09$; women: $\mathrm{OR}=0.64 ; 95 \% \mathrm{CI}, 0.25-1.62)$. A decreased risk also was found for women, but not for men, who took NSAIDs to treat arthritis (women: $\mathrm{OR}=0.13 ; 95 \% \mathrm{CI}$, 0.05-0.36; men: $\mathrm{OR}=1.0$ ).

Information on tumor size was routinely available from four of the five participating hospitals. Of 356 case patients $(70 \%)$, no significant differences in stage were found between NSAID users and other case patients. Of 50 case patients with Stage 1 tumors, only $6 \%$ were NSAID users, compared with $13 \%$ of case patients with larger tumor diameters.

The ORs for daily acetaminophen use among subjects who did not take NSAIDs were 1.07 (95\% CI, $0.35-3.23$ ) for men and 0.59 (95\% CI, 0.27-1.25) for women (Table 3 ). When stratifying by years of daily acetaminophen intake, there was little heterogeneity in risk. Acetaminophen was taken by both men and women primarily to treat arthritis and headache pain.

The association of large bowel cancer with other suspected risk factors was evaluated to determine possible confounding in the data. No association was observed with body mass index and dietary intake of red meat, cheese, fruits, and vegetables. There was no association with levels of physical activity, cigarette smoking, alcohol consumption, and coffee consumption. Family history of colorectal cancer was related significantly to the risk of colorectal cancer $(\mathrm{OR}=2.8 ; 95 \%$ $\mathrm{CI}, 1.8-4.2$ ) but unrelated to pain reliever use. A greater proportion of female control subjects had a history of rheumatoid arthritis, as compared with case patients $(8.4 \%$ vs. 3.1$)$, although the proportion of NSAID users was the same in both rheumatoid arthritis groups. ${ }^{29}$

\section{Discussion}

Our data are consistent with most previous epidemiologic studies that found a reduced risk of colon cancer or colorectal cancer among regular users of aspirin or NSAIDs. ${ }^{18-22}$ We found little differences in the odds ratios when comparing the risk between left-sided and right-sided colon cancers, or between cancers of the colon and rectum.

While our results support the hypothesis that regular NSAID intake reduces the risk of large bowel cancer, the evidence that the protective effect increases with the duration of use has not been established. Some of the epidemiologic studies of NSAID use did not examine 
the risk by the duration of NSAID intake. In studies conducted by Rosenberg et al. ${ }^{19}$ and Thun et al., ${ }^{21}$ nonsignificant trends were found with increasing duration of NSAID use. In our study, the risk reduction among men increased with long term NSAID use ( $>9$ years). However, we found a greater protective effect among women who took NSAIDs for 1-9 years compared with women who used them for more than 9 years. Our data show that, at least for men, the reduction in risk increases with the duration of NSAID use.

The relatively large risk reduction among women who used NSAIDs regularly for up to 9 years was attributable to the low prevalence of NSAID use among female case patients. Only 3 of 228 female case patients took NSAIDs regularly for 1-4 years, and 1 female case patient took NSAIDs for 5-9 years. The low prevalence of regular NSAID use in female cases $(7 \%)$ may reflect a sampling bias. Twenty-one percent of 102 female case patients in the study conducted by Paganini-Hill et al. ${ }^{23}$ used aspirin regularly. The proportion of daily aspirin users in the American Cancer Society cohort ${ }^{20,21}$ (9\% of 257 female case patients) was similar to our findings, although these study subjects were, on average, younger than those in our study ( 57 years vs. 64 years). To help interpret the results from these and other epidemiologic studies of NSAID use, population-based data of aspirin intake should be gathered to determine the extent to which these various study findings can be generalized. The possibility of selection bias in our study also may be reflected in the ratio of colon to rectal cancers. This ratio was $2: 1$ in our study, compared with $1: 5^{19}$ and $1: 4,^{22}$ respectively, in two other case-control studies of NSAID use.

One possible reason why a significant trend with duration of NSAID intake may be difficult to detect in epidemiologic studies is that NSAIDs taken regularly at younger ages and before the formation of neoplastic polyps or de novo cancers arising from flat mucosa may not reduce the risk of colorectal cancer. Most clinical trials of aspirin-like compounds have been conducted with patients who have existing colonic lesions. For example, case reports and clinical trials with a small number of patients have demonstrated that sulindac, a NSAID, reduces the size and number of polyps in patients with familial polyposis when administered daily. ${ }^{30-33} \mathrm{~A}$ clinical trial of 793 patients with adenomas showed that regular aspirin users had a lower risk of new adenomas after a 1-year follow-up. ${ }^{26}$ However, one recent study did show that aspirin use for 5 years or longer inhibited the formation of adenomatous polyps. ${ }^{25}$ This association should be examined in other populations. Because the mechanisms by which NSAIDs potentially inhibit adenomas or colon tumor growth is unclear, the question on duration of use requires further study.

Another important consideration in studies of aspirin and colorectal cancer is whether the observed association is due to uncontrolled confounding. For example, persons taking NSAIDs to prevent heart disease may have different dietary and lifestyle habits than persons who take NSAIDs to treat pain. Our findings do not support this hypothesis, because a risk reduction was found for women who took NSAIDs for preventive purposes and for treating arthritic and headache pain. Similarly, men who used NSAIDs regularly for preventive purposes or the treatment of headache pain had a reduced risk of colorectal cancer. Most of these findings were not statistically significant because there was lower statistical power to detect associations in subgroup analysis. Our findings should be supplemented with population-based data that determine the reasons why people use NSAIDs and whether NSAID users differ from nonusers with respect to diet, smoking and alcohol intake, regularity of physician visits, allergic reaction to aspirin, medical history, and various lifestyle habits.

A common concern in studies of NSAIDs and colorectal cancer mortality is whether aspirin use induces gastrointestinal bleeding and, as a consequence, would lead to a detection bias. Such a bias would reduce the magnitude of any association between NSAID use and colorectal cancer. We observed no statistical differences between NSAID use and stage of disease. In fact, NSAID users were somewhat less likely to have been diagnosed with early stage tumors.

Our hospital controls were selected on the basis of diseases or conditions that were considered unrelated to aspirin use. Excluded diagnoses included cardiovascular disease, arthritis, and headaches. There may be other types of diseases or conditions among the hospital control subjects that are related to aspirin use, although there is little information to determine this. It is expected that the frequency and duration of aspirin use among hospital control subjects would vary, as it does in the general population. Two lines of evidence indicate, however, that the choice of hospital control subjects did not result in a spurious association between colorectal cancer and NSAID intake. First, $20 \%$ of both male and female control subjects were regular NSAID users. This percentage is similar to the user rate among the population-based control subjects of the Cancer Prevention Study II. ${ }^{20}$ Secondly, except for the patients with benign prostatic hyperplasia and female patients with cancer, the frequency of NSAID use was greater among all the control subgroups than cases. Still, the suitability of some controls, especially cancer controls in studies of NSAID use may be somewhat problematic. 
However, Rosenberg et al. ${ }^{19}$ found no differences in risk when comparing cases to either cancer control subjects or noncancer control subjects. This group previously found no effect of NSAID use on other cancers. ${ }^{34}$ A Finnish study of patients with rheumatoid arthritis found significantly reduced incidences of colon, rectum, and stomach cancers, but not of other cancers. ${ }^{35}$

Control patients admitted for slipped disks used NSAIDs more often than other control subjects (36\% vs. $19 \%$ ). A slipped disk is an acute condition that was not related to chronic aspirin use in this study. Among these patients who regularly took NSAIDs, six of seven men $(86 \%)$ and eight of nine women $(89 \%)$ took NSAIDs to treat arthritis pain. These results suggest that in this study, arthritis may be a risk factor for a slipped disk. If the 44 controls who were diagnosed with slipped disk were eliminated from the analysis, however, the NSAID exposure rate for the entire control series would be reduced only from $20 \%$ to $19 \%$.

The association between acetaminophen intake and large bowel cancer is more difficult to assess than that for NSAIDs, because acetaminophen is used less frequently among middle-aged and older men in the general population (McNeil Consumer Product Company, unpublished data, 1992). Some acetaminophen products are compounded with aspirin, and a few patients took both aspirin and acetaminophen to treat a particular illness. In the American Cancer Society studies, ${ }^{20,21}$ there was no decrease in colon cancer rates among users of acetaminophen, although there was insufficient information to assess the risk for frequent acetaminophen users. In our study, women who took acetaminophen daily had a lower but nonsignificant reduced risk of colorectal cancer. There were not enough male patients who took acetaminophen regularly to evaluate this association adequately. These findings suggest that a possible protective mechanism for acetaminophen cannot be ruled out at this time. Acetaminophen has been suggested to be a prostaglandin formation inhibitor, ${ }^{17}$ and earlier studies of laboratory rats that were fed the carcinogen $\mathrm{N}$-2-fluorenylacetamide showed that acetanilide, a parent compound of acetaminophen, inhibited liver tumor formation and increased survival time. ${ }^{36,37}$ The association with acetaminophen could be examined with greater statistical power in a population with a high prevalence of arthritis, such as older women.

\section{References}

1. Kudo T, Narisawa T, Abo S. Antitumor activity of indomethacin on methylazoxymethanol-induced large bowel tumors in rats. Gann 1980; 71:260-4.

2. Narisawa T, Sato M, Tani M, Kudo T, Takahashi T, Goto A. In- hibition of development of methylnitrosurea-induced rat colon tumors by indomethacin. Cancer Res $1981 ; 41: 1954-7$.

3. Pollard M, Luckert PH. Effect of piroxicam on primary intestinal tumors induced in rats by N-methylnitrosurea. Cancer Lett 1984; 25:117-21.

4. Pollard M, Luckert PH. Prolonged antitumor effect of indomethacin on autochthonous intestinal tumors in rats. I Natl Cancer Inst 1983; 70:1103-5.

5. Pollard M, Luckert PH, Schmidt MA. The suppressive effect of piroxicam on autochthonous intestinal tumors in the rat. Cancer Lett 1983; 21:57-61.

6. Nigro ND, Bull AW, Boyd ME. Inhibition of intestinal carcinogenesis in rats: effect of difluoromethylornithine with piroxicam or fish oil. I Natl Cancer Inst 1986; 77:1309-13.

7. Reddy BS, Nayini J, Tokumo K, Rigotty J, Zang E, Kelloff G. Chemoprevention of colon carcinogenesis by concurrent administration of piroxicam, a nonsteroidal antiinflammatory drug with DL-\&-diflouromethylornithine, an ornithine decarboxylase inhibitor, in diet. Cancer Res 1990; 50:2562-8.

8. Rao CV, Tokumo K, Rigotty J, Zang E, Kelloff G, Reddy BS. Chemoprevention of colon carcinogenesis by dietary administration of piroxicam, \&-diflouromethylornithine, 16\&-flouro5-androsten-17-one, and ellagic acid individually and in combination. Cancer Res 1991; 51:4528-34.

9. Moorghen $M$, Ince P, Finney KJ, Sunter JP, Appleton DR, Watson AJ. A protective effect of sulindac against chemically-induced primary colonic tumors in mice. J Pathol 1988; 156:341-7.

10. Reddy BS, Maruyama H, Kelloff G. Dose-related inhibition of colon carcinogenesis by dietary piroxicam, a nonsteroidal antiinflammatory drug, during different stages of rat colon tumor development. Cancer Res 1987; 47:5340-6.

11. Lombardino JG, Wiseman EH. Piroxicam and other anti-inflammatory oxicams. Med Res Rev 1982; 2:127-52.

12. Carter CA, Ip M, Ip C. A comparison of the effects of the prostaglandin synthesis inhibitors indomethacin and carprofen on 7,12-dimethylbenz[a]anthracene-induced mammary tumorigenesis in rats fed different amounts of essential fatty acid. Carcinogenesis (Lond) 1989; 10:1369-74.

13. Reddy BS, Rao CV, Rivenson A, Kelloff G. Inhibitory effect of aspirin on azoxymethane-induced colon carcinogenesis in F344 rats. Carcinogenesis 1993; 14:1493-7.

14. Lupulescu A. Enhancement of carcinogenesis by prostaglandins. Nature $1978 ; 272: 634-6$.

15. Craven PA, Saito R, DeRubertis FR. Role of local prostaglandin synthesis in the modulation of proliferative activity of rat colonic epithelium. J Clin Invest 1983; 72:1365-76.

16. Plesdia OJ, Smith AH, Grinwich K. Subversion of immune system by tumor cells and the role of prostaglandins. Proc Natl Acad Sci $1975 ; 75: 1848-51$.

17. Clissold SP. Paracetamol and phenacetin. Drugs 1986;32:46-59.

18. Kune GA, Kune S, Watson LF. Colorectal cancer risk, chronic illnesses, operations, and medications: case-control results from the Melbourne Colorectal Cancer study. Cancer Res 1988; 48: 4399-404.

19. Rosenberg L, Palmer JR, Zauber AG, Warshauer ME, Stolley PD, Shapiro S. A hypothesis: nonsteroidal anti-inflammatory drugs reduce the incidence of large bowel cancer. I Natl Cancer Inst $1991 ; 83: 355-8$.

20. Thun MJ, Namboodiri MH, Heath $\mathrm{CW}$. Aspirin use and reduced risk of fatal colon cancer. N Engl J Med 1991; 325:1593-6.

21. Thun MJ, Namboodi MM, Calle EE, Flanders WD, Heath CW. Aspirin use and risk of fatal cancer. Cancer Res 1993; 53:1322-27.

22. Suh O, Mettlin C, Petrelli NJ. Aspirin use, cancer, and polyps of the large bowel. Cancer 1993; 72:1171-7. 
23. Paganini-Hill A, Hsu G, Ross RK, Henderson BE. Aspirin use and incidence of large bowel cancer in a California retirement community. J Natl Cancer Inst 1991; 83:1182-3.

24. Gann PH, Manson JE, Glynn RJ, Buring JE, Hennekens $\mathrm{CH}$. Low-dose aspirin and incidence of colorectal tumors in a randomized trial. I Natl Cancer Inst 1993; 85:1220-4.

25. Logan RFA, Little J, Hawtin PG, Hardcastle JD. Effect of aspirin and non-steroidal anti-inflammatory drugs on colorectal adenomas: case-control study of subjects participating in the Nottingham faecal occult blood screening programme. Br Med J 1993; 307:285-289.

26. Greenberg ER, Baron JA, Freeman DH Jr, Mandel JS, Haile MR. Reduced risk of large-bowel adenomas among aspirin users. J Natl Cancer Inst 1993; 85:912-6.

27. Breslow NE, Day NE. Statistical methods in cancer research. Vol I. The analysis of case-control studies. Lyon, France: International Agency for Research on Cancer, 1977.

28. Wacholder S, Silverman DT, McLaughlin JK, Mandel JS. Selection of controls in case-control studies, II: types of controls. Am JEpidemiol 1992; 135:1029-41.

29. Muscat JE, Wynder EL. Correspondence re: anti-inflammatory drugs and rheumatoid arthritis. J Natl Cancer Inst 1993; 85:9212.

30. Waddell WR, Loughry WR. Sulindac for polyposis of the colon. J Surg Oncol 1983; 24:83-7.
31. Waddell WR, Gasner GF, Cerise EJ, Loughry RW. Sulindac for polyposis of the colon. Am J Surg 1989; 157:175-8.

32. Labayle D, Fischer D, Vielh P, Drouhin F, Pariente A, Borier C, et al. Sulindac causes regression of rectal polyps in familial adenomatous polyposis. Gastroenterology 1991; 101:635-9.

33. Giardiello FM, Hamilton SR, Krush AJ, Piantadori S, Hylind LM, Celano $P$, et al. Treatment of colonic and rectal adenomas with sulindac in familial adenomatous polyposis. N Engl J Med 1993; 328:1313-6.

34. Slone D, Shapiro S, Miettinen OS. Case-control surveillance of serious illnesses attributable to ambulatory drug use. In: Columbo F, Shapiro S, Slone D, editors. Epidemiological evaluation of drugs. Amsterdam: Elsevier/North Holland Biomed Press, 1977: 59-70.

35. Gridley G, McLaughlin JK, Ekbom A, Klareskog L, Adami HO, Hasker DG, et al. Incidence of cancer among patients with rheumatoid arthritis. I Natl Cancer Inst 1993; 85:307-11.

36. Yamamoto RS, Glass RM, Frankel HH, Weisburger EK, Weisburger $\mathrm{JH}$. Inhibition of the toxicity and carcinogenicity of N-2 fluorenylacetamide by acetanilide. Toxicol Appl Pharmacol 1968; 13:108-17.

37. Yamamoto RS, Williams GM, Richardson HL, Weisburger EK, Weisburger JH. Effect of p-hydroxyacetanilide on liver cancer induction by $\mathrm{N}$-hydroxy- $\mathrm{N}$-2-fluorenylacetamide. Cancer Res $1973 ; 33: 454-7$. 